\title{
A LOGÍSTICA REVERSA E O ENFRENTAMENTO DO FENÔMENO DA OBSOLESCÊNCIA PROGRAMADA
}

\section{REVERSE LOGISTICS AND THE FACING OF THE PHENOMENON OF PROGRAMMED OBSOLESCENCE}

\author{
Sinara Lacerda Andrade ${ }^{1}$ \\ Gabriela Eulalio De Lima²
}

\section{Resumo}

A pesquisa partiu da análise sociológica realizada por Zygmunt Bauman que determinou os meandros e limitações da sociedade de consumo. Objetivou avaliar as consequências causadas pela influência das novas tecnologias, a fim de aprimorar o setor produtivo que - sob o respaldo da pós-modernidade e preocupado, sobretudo, com o desenvolvimento econômico - vem fomentando o mercado de consumo com o fenômeno da obsolescência programada que se substancializa na redução proposital da durabilidade dos bens, promovendo riscos socioambientais representados tanto pela extração dos recursos naturais, como também, pelo descarte inadequado dos resíduos. Ante esta problemática, ponderou-se a eficácia da Lei Federal n.o 12.305 de 02 de agosto de 2010, especialmente quanto ao instrumento da logística reversa, entendendo tratar-se de mecanismo legal apto a satisfazer as necessidades da sociedade de consumo sem arriscar a existência humana digna, tendo-se em vista a preocupação com todo o ciclo de vida dos produtos, traduzindo maior eficácia na regulação da produção e do consumo, visando o desenvolvimento econômico e social. A pesquisa desenvolveu-se sob o método dedutivo, com apoio bibliográfico e na legislação brasileira, que ainda que de forma tímida, enfrenta a problemática dentro dos limites no Estado Brasileiro.

Palavras-chave: Logística Reversa; Novas tecnologias; Obsolescência; Sociedade de consumo; Sustentabilidade.

\begin{abstract}
The research started from the sociological analysis carried out by Zygmunt Bauman that determined the meanders and limitations of the consumer society. The objective of this study was to evaluate the consequences of the influence of new technologies in order to improve the productive sector, which - under the support of postmodernity and concerned above all with economic development - has been fomenting the consumer market with the phenomenon of
\end{abstract}

\footnotetext{
${ }^{1}$ Doutoranda em Empreendimentos Econômicos, Processualidade e Relações Jurídicas pela Universidade de Marília/SP (UNIMAR). Professora Assistente do Programa de Mestrado em Direito da Universidade de Marília/SP (UNIMAR) (2017). Mestre em Empreendimentos Econômicos, Processualidade e Relações Jurídicas pela Universidade de Marília/SP (UNIMAR) (2016). Associada ao Conselho Nacional de Pesquisa e Pós-graduação em Direito (CONPEDI). E-mail: sinaralacerda.adv@hotmail.com

${ }^{2}$ Mestre em Direito com a linha de pesquisa Empreendimentos Econômicos, Processualidade e Relações Jurídicas pela Universidade de Marília - UNIMAR (2016), Marília/SP. Associada do Conselho Nacional de Pesquisa e Pós-Graduação em Direito - CONPEDI desde 2014. Avaliadora de manuscritos submetidos à Revista de Direito da Cidade - Qualis A1, à Revista da Faculdade de Direito da UFRGS - Qualis B1, à Revista da Faculdade de Direito da UFG - Qualis A2 e à Revista Brasileira de Sociologia do Direito - Qualis B1. Advogada regularmente, inscrita na OAB/MG n.o 138.790. E-mail: gabrielaeulalio.adv@ hotmail.com
} 
programmed obsolescence is substantialized in the purposive reduction of the durability of the goods, promoting socioenvironmental risks represented by both the extraction of natural resources and the inadequate waste disposal. Faced with this problem, we considered the effectiveness of Federal Law No. 12,305 of August 2, 2010, especially regarding the reverse logistics instrument, considering it to be a legal mechanism able to meet the needs of the consumer society without risking dignified human existence, taking into account the concern with the whole life cycle of products, translating greater efficiency in the regulation of production and consumption, aiming at economic and social development. The research developed under the deductive method, with bibliographical support and in the Brazilian legislation, that although of timid form, faces the problematic within the limits in the Brazilian State.

Keywords: Reverse logistics; New technologies; Obsolescence; consumer Society; Sustainability.

\section{INTRODUÇÃO}

A discussão abordada na pesquisa parte da análise realizada por Zygmunt Bauman e do conceito social contemporâneo, que a reconhece como sociedade de consumo (BAUMAN, 2007, p. 105), relevando sua definição sob a influência das novas tecnologias, movimento impresso na Era Pós-Moderna, que impulsiona o mercado de consumo e os indivíduos a permanecerem em um estado temporal sempre futurista, por condicionar o setor produtivo e o consumidor a buscarem bens cada vez mais novos, substituindo aqueles ainda aptos e viáveis ao uso, resultando daí o fenômeno da obsolescência.

Os estudos do sociólogo apontam para uma sociedade líquida, ou seja, uma sociedade em que as realizações pessoais não se baseiam em aspectos sólidos, isso em razão da mutação repentina do status das coisas, relacionamentos e bens de consumo; resultando numa existência fluida, ou seja, uma vida inserida num contexto de reinícios. (BAUMAN, 2007, p. 7/8)

Ocorre que, nesta tendência social de possuir cada vez mais, saltando do critério do consumo por necessidade pura para a patologia do consumismo, desponta uma sociedade que enxerga no ato de consumo a razão ideal de satisfação para a busca perfeita do sentimento da felicidade; impera a cultura do descarte prematuro daquilo que ainda é funcional, para adquirir o que de mais moderno o mercado de consumo oferece em cada novo momento, olvidando a sustentabilidade, nos seus três pilares: econômico, social e ambiental, e a imprescindibilidade do desenvolvimento do tripé de forma equilibrada. (ZAMBON, 2015, n.p.)

Percebe-se, portanto, que no momento que a sociedade hodierna se desenvolve calcada no consumo desenfreado e inconsciente alavancando o fenômeno da obsolescência 
como uma de suas causas, vigora o progresso. O aspecto econômico da sustentabilidade, todavia, coloca em risco os pilares ambiental e social, que via de consequência, arrisca e/ou anula as perspectivas das futuras gerações. (COSTA; TEODÓSIO, 2011, n.p.)

Neste passo, a problemática do artigo revela na necessidade de revitalizar a preocupação com as gerações presente e as vindouras, dedicando-se atenção à reconstrução da sociedade pós-moderna alicerçada numa base sustentável, propondo que a Lei Federal n.으 12.305/2010, através do instrumento da logística reversa, detém os mecanismos essenciais para gerir o atual contexto social, uma vez que aponta a responsabilidade num viés compartilhado pelos ciclos produtivos, evidenciando que o encargo é de todos a fim de manter o desenvolvimento sustentável e reestabelecer a ordem social.

Assim, o objetivo do trabalho manifesta-se na intenção de compreender o contexto social atual e a necessidade de revertê-lo para uma didática sustentável, sem olvidar da preocupação prevalente com a ordem econômica, alinhando a justificativa da pesquisa na prudência que se deve imperar para esta sociedade e a sua posteridade.

Salienta-se, por fim, que a pesquisa desenvolver-se-á sob o método dedutivo, buscando subsídios na bibliografia que contribuirão com o tema para melhor compreender o contexto teórico, valendo-se também da análise na legislação brasileira que ainda que de forma tímida, enfrenta a problemática dentro dos limites da Federação.

\section{A SOCIEDADE PÓS-MODERNA E AS NOVAS TECNOLOGIAS}

A pós-modernidade, formada da condição sociocultural e estética, dominante no capitalismo logo após a queda do Muro de Berlim em 1989, rege a sociedade de consumo hodierna. Despontando a condição livre e pessoal do indivíduo de desenvolver o ato de consumir para a sua construção do universo particular e sociocultural, diferentemente do que acontecia na modernidade. (BRESSER-PEREIRA, 2014, n.p.)

Zygmund Baumam, evidenciando a diferença entre estes períodos, apresenta os malestares da modernidade e os da pós-modernidade:

Os mal-estares da modernidade provinham de uma espécie de segurança que tolerava uma liberdade pequena demais na busca da felicidade individual. Os mal-estares da pós-modernidade provêm de uma espécie de liberdade de procura do prazer que tolera uma segurança individual pequena demais. (BAUMAN, 1998, p. 10)

Percebe-se que é na Era Pós-Moderna que a sociedade de consumo vê manifestar os efeitos da definição de liberdade dos sujeitos, que revestidos da liberdade individual acentuada, 
buscam no consumo a esperança de satisfazerem além das suas necessidades puras, mas, sobretudo, os desejos humanos, coisificando o conceito de dignidade.

O papel das novas tecnologias no cenário pós-moderno é alavancar a cultura do consumismo, isso por sua força de alcance; aprimorando o setor produtivo para lançarem bens de consumo cada vez mais atrativos e menor duráveis ao indivíduo consumidor, que entra num ciclo vicioso do ato de consumir. Esta ação mercadológica, contudo, leva em consideração a deliberação de manter vivo o pilar econômico da sustentabilidade, primando pela promoção ativa do aumento dos lucros, desprezando-se, para tanto, os pilares ambiental e social, que vêm sofrendo gradativamente os efeitos do consumo reiterado e desnecessário, objeto propulsor da cultura do consumismo. (JACOBI, 2006, n.p.)

Ideologicamente, são as mudanças sociais geradas pelos tempos contemporâneos com a influência das novas tecnologias que estão impulsionando o consumo para um formato exagerado, daí afirmar notadamente pelo império da cultura do consumismo, desmistificando a prática essencial do ato de consumo puro para o seu cometimento reiterado.

As novas tecnologias acompanhadas dos meios de comunicação e as fontes em geral de informação, formam o grupo das principais responsáveis pela derivação do consumo contemporâneo; consequência da expansão da visão do indivíduo para uma concepção de vida futurista, isso em razão da disposição abundante do mercado de consumo, que mantém a disposição dos consumidores um rol inexaurível de bens cada vez mais modernos e sedutores, porém pouco duráveis, promovendo o desenvolvimento econômico no fenômeno da obsolescência programada. (REIS; CASTRO, 2004, n.p.)

O fato é que, embora na Era Pós-Moderna todo o contexto social esteja intimamente conectado ao consumo, sendo identificado como pressuposto da existência humana, o comportamento exagerado dos consumidores tem originado diversos problemas de cunho ambiental, social, moral para a sociedade contemporânea.

Ora, esta condição existencial, partindo do ter/possuir, é mais complexa do que se percebe numa visão superficial. A obsessão pelo consumo, em cadeia reiterada, evidencia com mais fulgor a desigualdade social, suscita o meio ambiente riscos diversos e como resultado último, mitiga a própria existência humana da sua proliferação. Portanto, a variação do consumo sair do papel de cumprir com as necessidades puras para o atributo intrínseco na busca do sentimento individualista e liberal demais, diferencia a sociedade-cultura de consumo moderna da pós-moderna. (RUSCHEINSKY, 2010, n.p.) 
As mudanças de conceitos, individual e social, alavancam e despontaram as novas tecnologias, que numa visão passiva do mercado de consumo, possibilita o indivíduo acesso cada vez mais facilitado aos bens de consumo - apenas com um clique é possível adquirir bens e contratar serviços de forma cada vez mais fácil e rápida.

Numa outra vertente, as novas tecnologias também exercem forte influência para ditar os desejos e as "necessidades" no universo do consumo, seduzindo os consumidores para a prática inconsciente e desenfreada. Destarte, o indivíduo preocupado apenas com o processo de identificação pessoal e inserção social, consome cada vez mais, descartando seus bens "antigos" ainda aptos ao uso, ignorando completamente a questão do uso de insumos para o processo de fabricação dos objetos adquiridos e o fim dos bens descartados.

A dinâmica criada pelas novas tecnologias na sociedade contemporânea ao atrair o consumidor para o mercado em constante inovação, prima por aquecer o aspecto econômico da sustentabilidade através do aumento da margem de lucros, porém os efeitos negativos têm sido suportados pelo meio ambiente e pelo gênero humano, a finitude dos recursos naturais compromete o futuro das gerações, fragilizando a concepção de dignidade humana no aspecto social.

Hodiernamente, os bens surgem no mercado de consumo numa sequência ilógica, motivada pelas novas tecnologias, outros bens substituem aqueles que ainda estão aptos e viáveis ao uso, tornando-os ultrapassados momento subsequente de serem retirados do mercado. Este movimento mercadológico aponta para o consumidor, a necessidade do bem útil, porém obsoleto, ser descartado.

No processo de produção não há a preocupação com a finitude dos recursos; no consumo propriamente dito, não existe por parte dos agentes sociais e econômicos, uma ação consciente sobre o que, o quanto e quando deve-se consumir, tampouco quando o bem realmente está passível de ser trocado, deslembrando-se igualmente a destinação final do bem descartado.

Sobre os efeitos do descarte, Rachel Botsman e Roo Rogers elucidam seus efeitos no Oceano Pacífico:

Bem no meio do Oceano Pacífico, um pouco a leste do Japão e a oeste do Havaí, formou-se um gigantesco monumento dos resíduos do consumismo moderno. A grande mancha de lixo do Pacífico é o maior depósito de lixo do mundo, apesar de não ser em terra, mas sim, no oceano. Estima-se que este turbilhão de lixo tenha aproximadamente o dobro do tamanho do Texas e, em algumas partes, chegue a mais de 30 metros de profundidade, se não mais. Trata-se de uma confusão 
flutuante de 3.5 milhões de toneladas de lixo, sendo $90 \%$ compostos de plásticos, de tampas de garrafas e brinquedos a sapatos, isqueiros, escovas de dentes, redes, chupetas, invólucros, embalagens para viagem e sacolas de compras de todos os cantos do mundo. (BOTSMAN; ROGERS, 2011, p. 3)

O tema também foi abordado por Cosima Dannoritzer no documentário "Comprar, tirar, comprar: la historia secreta de la obsolescencia programada", que demonstrou o resultado da obsolescência no fluxo de resíduos eletrônicos em países de terceiro mundo, trazendo Gana país da África ocidental como exemplo. O documentário destaca que os países de primeiro mundo, tomando por base o argumento de que os eletrônicos ainda estão aptos para uso, os consideram produtos de segunda mão e enviam para os países subdesenvolvidos, alegando que poderão usufruir da utilidade daqueles bens. Todavia, o documentário mostra que mais de $80 \%$ (oitenta por cento) dos bens que chegam em Gana não têm conserto e são descartados, formando um amontoado de lixo eletrônico. (COMPRAR, 2011, 37min52s)

Dentro dos limites do Estado Brasileiro é possível compreender os efeitos das novas tecnologias no contexto social e o fenômeno da obsolescência, a partir dos dados divulgados pelo Instituto Brasileiro de Defesa do Consumidor - IDEC e a Market Analysis, que através de uma pesquisa baseada em entrevistas, identificou-se que $81 \%$ (oitenta e um por cento) dos consumidores, antes mesmo de buscarem pela assistência técnica e com menos de 3 (três) anos de uso trocam de aparelho celular, sendo este o produto com a vida útil mais comprometida, com durabilidade média de 3 (três) anos, sendo que raramente ultrapassa os 5 (cinco) anos. (IDEC; MARKET ANALYSIS, 2003, n.p.)

Com relação a troca de aparelhos, a pesquisa identificou, levando em consideração o critério do gênero, que as mulheres se pautam na causa do funcionamento, maioria em ralação aos homens (60\% versus 53\%); os homens, contudo, são impulsionados pelo aspecto da novidade (55\% versus $47 \%$ ); a classe mais baixa têm nos problemas de funcionamento a motivação para a ação da troca (66\% versus $53 \%$ ) e a alta se movimenta com base na atualidade tecnológica (59\% versus 46\%). Para os demais aparelhos: os eletrodomésticos, digitais e eletrônicos, a procura pela assistência ocorre em 77\%, 73\% e 56\%, respectivamente. Todavia, a propósito do enfoque do debate no trabalho em tela, a pesquisa popular apontou que somente $1 \%$ dos descartes dos aparelhos digitais e celulares é realizado em pontos peculiares de coleta, 2\% dos eletroeletrônicos e 5\% dos eletrodomésticos. (IDEC; MARKET ANALYSIS, 2003, n.p.)

Ilustrando a temática, realçando o destino dos bens de consumo a pesquisa finalizou analisando quatro categorias (doação ou venda, manter guardado, descarte, nenhuma alternativa): a) Digitais: $63 \%$ doou ou vendeu, $21 \%$ deixou guardado, $15 \%$ descartou, $1 \%$ 
nenhuma das alternativas; b) Eletroeletrônicos: 45\% doou ou vendeu, 31\% deixou guardado, 21\% descartou, 3\% nenhuma das alternativas; c) Celular: 30\% doou ou vendeu, $41 \%$ deixou guardado, $13 \%$ descartou, $14 \%$ foi perdido ou roubado, $1 \%$ nenhuma das alternativas; e d) Eletrodomésticos: 74\% doou ou vendeu, 5\% deixou guardado, 15\% descartou, 6\% nenhuma das alternativas. (FORENSE, 2014, n.p.)

Os resultados apurados dão a compreensão de que a sociedade de consumo pósmoderna influenciada pelas novas tecnologias, o pilar econômico vem sendo sustentado fortemente pelo fenômeno da obsolescência, arriscando iminentemente as gerações vindouras com os reflexos negativos que refletem aos aspectos ambiental e social da sustentabilidade, que sofrem com a escassez dos recursos, longevidade da decomposição dos bens descartados e mudança de valores, evidenciada com o individualismo acentuado dos consumidores, preocupados com a satisfação própria e momentânea, sem considerar as necessidades do coletivo e do futuro das gerações.

\section{OBSOLESCÊNCIA ENQUANTO FENÔMENO}

Como visto, a cultura do consumismo origina a do descarte, que juntas impulsionam o pilar econômico, para tanto, contam com uma cadeia de produção de bens cada vez mais frágeis, mais atrativos e menos duráveis, instigando o indivíduo a desejar e precisar consumir rotativamente os bens novos lançados no mercado.

Os produtos não possuem a mesma vida útil dos tempos remotos, originando a denominada obsolescência programada, que nada mais é que a redução proposital da durabilidade do bem de consumo; prática que ao longo do tempo demonstrou ser imprescindível para aumentar a produção e o consumo, estimulando precipuamente a economia. (BELLANDI; AUGUSTIN, 2015, n.p.)

Características como durabilidade, força e resistência, que em outros tempos eram requisitos essenciais para a produção de bens de consumo, atualmente são vistos como elementos prejudiciais para o desenvolvimento econômico; primeiro, porque o estilo fordista de produção, a reconhecida produção em série, visa produzir o maior número de bens em um menor espaço de tempo, impossibilitando que neste espaço de tempo reduzido, se produza bens de boa qualidade e durabilidade; segundo, a produção em massa significa "bens em grande escala", e essa fabricação deve ser rapidamente escoada para manter aceso o pilar econômico através do nível cada vez mais elevado do consumo, mas que, contudo, só é possível 
graças a redução da vida útil dos bens, para que estes sejam frequentemente substituídos por novos.

Neste contexto da sociedade de consumo, também deve-se levar em conta o anseio dos consumidores, investidos de ambições cada vez mais inexauríveis, resultando uma relação irresponsável entre fornecedores e consumidores com as gerações futuras, daí subdividindo o fenômeno da obsolescência em programada e psicológica.

Comprovando que a teoria da obsolescência é destinada como base fundamental para o pilar econômico não ser recente, Vance Pakard, na década de 60 realizou estudos que já apontava o fenômeno da obsolescência programada como um dos princípios da economia de crescimento. Seu sucessor Giles Slade, na sua obra "Feito para Quebrar", demonstrou que a estratégia da obsolescência programada é utilizar as mais diversas técnicas para reduzir artificialmente a durabilidade de produtos manufaturados com o objetivo de estimular $\mathrm{o}$ consumo repetitivo. (SLADE, 2006, p. 05)

Pois bem, a propósito da compreensão de obsolescência programada, revela-se na ação intencional de reduzir a vida útil dos produtos, trata-se, portanto, da diminuição artificial da durabilidade dos bens de consumo; (SIMS, 2013, n.p.) é a estratégia para tornar um bem ainda útil arcaico, seja pela inserção de novas tecnologias ou pelo aperfeiçoamento do design, cujo objetivo é induzir o consumidor a adquirir novos produtos antes que os "antigos" estejam de fato inutilizáveis, fomentando o consumismo que resulta no círculo "aquisição-descarte".

Historicamente, a lâmpada inaugurou a era da obsolescência programada - os primeiros protótipos foram produzidos com durabilidade e resistência determinadas, um filamento apto para durar até 2500 (duas mil e quinhentas) horas. (LIMA; ANDRADE, 2015, p. 140) Cosima Dannoritzer, em seu documentário "Comprar, tirar, comprar: la historia secreta de la obsolescencia programada", aponta que em 1924 surgiu o primeiro cartel do mundo, denominado Phoebus, que tinha a intenção de controlar a produção de lâmpadas; integrado por fabricantes dos Estados Unidos da América e da Europa, estimularam a redução da vida útil das lâmpadas em apenas 1000 (mil) horas. O que por consequência, obrigaria os indivíduos a consumirem mais lâmpadas, aumentando as vendas e os lucros. (COMPRAR, 2011, 17min33s)

Em 1929, no período da mais intensa recessão norte americana, após a quebra da bolsa, havia disponível um volume alarmante de bens estocados nos depósitos dos seus fabricantes. Nesse período ter em depósito produtos que não se deterioravam era uma tragédia. Bernand London, um empresário norte americano concluiu que a única solução para estimular o consumo, era tornar a estratégia da obsolescência programada uma prática 
compulsória, assim todos os produtos obrigatoriamente deveriam ter uma vida útil limitada, os consumidores devolveriam os produtos obsoletos ao governo para que fossem destruídos, porém devido seu ao caráter antiético e amoral, a ideia nunca foi efetivamente implementada.

Na década de 50, a estratégia da obsolescência programada surge novamente, mas agora com uma diferença fundamental, não havia mais a necessidade de incentivar o consumo, mas sim, instigar o indivíduo a consumir em alta escala, seduzindo-o por meio do marketing, da publicidade de consumo e do design. A intenção do empresário americano nesta época era desenvolver uma insatisfação perene nos consumidores, fazendo com estes desejassem sempre o modelo do bem mais recente; a conquista da felicidade dependia intrinsicamente do consumo ilimitado. (GARCIA, 2014, n.p.)

A economia sustentava-se de táticas de estímulo do consumo, firmando a ideologia social que sempre haveria espaço para se adquirir mais bens, cultiva-se a política do excesso, da abundância, que resultou na resultando consequentemente na cultura do desperdício, do descarte prematuro, da prática da obsolescência programada.

Relevando a cultura do desperdício, a obsolescência programada, em razão da sua essência ideológica, prega que os produtos sejam descartados ainda que não tenha perdido sua finalidade de produção/criação. Portanto, quando um produto útil é descartado e enviado para um depósito de lixo, subentende-se que foram substituídos por outros bens, que logo também serão trocados e terão o mesmo destino. Este ciclo, contudo, gera um inconveniente à economia de crescimento, que apesar dos pontos positivos da inserção das novas tecnologias na sociedade pós-moderna, colabora com a prática reiterada do consumo, deslembrando que o impulso da produção possui como efeito colateral, o desfazimento e o descarte inadequado dos bens, promovendo o aumento deliberado do lixo eletrônico.

O fato é que, em uma sociedade capitalista, utópico seria defender a ideia de diminuição do consumo, porém deflagrar a sua prática, sem dedicar atenção aos pilares ambiental e social, coloca em risco acentuado as gerações futuras e a qualidade de vida destas. Portanto, o ideal e lógico, seria despontar uma cadeia de produção com materiais biodegradáveis ou de maior facilidade de decomposição, primando pela sustentabilidade socioambiental.

A substituição de produtos ainda úteis, porém obsoletos, implica no aumento da exploração de recursos naturais, fontes não renováveis, além de gerar o acúmulo de resíduos que serão descartados no meio ambiente. Deste modo, embora a produção, a circulação e o consumo de bens, atinjam a finalidade econômica, desiquilibra o princípio da sustentabilidade 
que é calcado em três pilares: econômico, social e ambiental (ELKINGTON, 2012, p. 20), e a inobservância de qualquer destes ou a fomentação desarmônica, avivará a crise socioambiental, arriscando as gerações futuras.

Por outro lado, a obsolescência por desejabilidade ou obsolescência psicológica é configurada no desejo do consumidor de adquirir novos bens, pela característica única de possuírem um design e/ou uma forma inovadora, ainda que possuam a mesma funcionalidade do objeto substituído. A obsolescência psicológica demonstra-se ser a mais complexa, pois está intimamente ligada a conduta humana súbita e arrebatadora do desejo pessoal.

A configuração deste tipo de obsolescência é percebida no desejo do consumidor de possuir sempre o produto que melhor satisfaça seus desejos. Assim, o simples fato do design dos produtos ter sido modificado, serve para induzir, instigar, seduzir os indivíduos a consumirem em escala reiterada. Veja-se que o produto se torna obsoleto não tecnicamente, mas tão somente na psique do consumidor, que é condicionado a associar o novo com o melhor e o velho com o pior.

Aspectos como estilo, aparência, forma e cores dos produtos, são as características mais importantes no bem e são utilizadas para seduzir o consumidor, que alienado passa a desejar sempre o que mais novo o mercado tiver. A obsolescência psicológica é configurada num universo da ilusão de mudança por meio da criação de um estilo, despertando no consumidor um sentimento de incômodo e desconforto ao utilizar um produto que se tornou "antigo", superado pela aparência do modelo novo.

Vance Packard, em sua obra "Estratégia do Desperdício", ao analisar a economia de crescimento na sociedade norte-americana, identificou os primeiros indícios da obsolescência psicológica:

[...] a pressa do sistema produtivo impossibilitava sistematicamente 0 desenvolvimento de melhoramentos significativos nos produtos existentes. Já naquela época, as modernizações frequentemente se limitavam a alterações e melhoramentos superficiais que pudessem ser aproveitados como sugestões de venda pelos redatores de publicidade [...].(PACKARD, 1965, p. 12)

No Brasil, o caso mais emblemático envolvendo o fenômeno da obsolescência, tem a empresa Apple Computer como protagonista, com o lançamento do iPad 4 poucos meses depois de colocar em circulação o iPad 3. Os usuários desse último produto, diante do lançamento de uma nova versão, que não apresentava consideráveis diferenças técnicas, exibindo apenas novo design, consideraram que o produto recém-adquirido (iPad 3), tornou-se obsoleto. Este fato motivou uma demanda judicial, distribuída em 06 de fevereiro de 2013 na 
12a Vara Cível de Brasília, que tramita em segredo se justiça sob o n. 2013.01.1.016885-2. Trata-se de uma Ação Civil, proposta pelo Instituto Brasileiro de Política e Direito da Informática, em face da fornecedora Apple Computer, objetivando a substituição do produto obsoleto. (MIGALHAS, 2013, n.p.)

O exemplo da Apple demonstra o grau de lesividade do fenômeno da obsolescência para a sociedade de consumo contemporânea, todos sofrem os seus efeitos. Ademais, frisa-se que seus resultados são diversos e danosos, intensificando a promoção do descarte prematuro dos bens obsoletos, o aumento do lixo tecnológico, o esgotamento dos recursos naturais e a perda dos valores humanos com o vigor do hiperindividualismo pós-moderno. Deste modo, o fenômeno da obsolescência e a prática do consumismo, originam à sociedade impactos diversos que ferem direitos de todos, arriscando a posteridade da vida humana, discussão que será adiante levantada.

\section{O ALCANCE JURÍDICO DO INSTRUMENTO DA LOGÍSTICA REVERSA}

Como explicitado no tópico anterior, o consumo é marca indelével da atual sociedade, indispensável ao desenvolvimento humano, sociocultural e econômico. Ocorre que, a sua prática desordenada dá origem a cultura do consumismo cujos danos ultrapassam a condição individual do consumidor e atinge os pilares social e ambiental. A existência humana vê-se condicionada a ação do ter/possuir; o meio ambiente sofre tanto com a extração elevada destes recursos pela cadeia de produção - provocando a escassez, como também pelo movimento do descarte - gerando amontoados de lixos sem a adequada destinação.

Com a promoção da inserção das novas tecnologias, a sociedade pós-moderna obstinada a alcançar resultados cada vez melhores para o desenvolvimento econômico, vê-se envolvida num processo mercadológico sedutor; o setor produtivo detém condições técnicas mais aprimoradas para lançar bens de consumo modernos e atrativos e, para manter aceso o objetivo do lucro, preocupam-se em reduzir da vida útil dos bens de consumo, praticando o fenômeno da obsolescência programada, alavancando uma gama de efeitos negativos e impactos socioambientais, principalmente no que concerne o volume de descarte do lixo eletrônico.

Por lixo eletrônico, compreende-se todo e qualquer material proveniente do descarte de produtos eletrônicos, seja pelo fenômeno da obsolescência, ou simplesmente, porque o produto de fato não cumpre mais com a finalidade para o qual foi fabricado. Este descarte, 
contudo, quase sempre é realizado de forma inadequada e esses produtos acabam em aterros sanitários ou lixões a céu aberto e nesses locais há grande concentração de substâncias tóxicas como chumbo, mercúrio, cádmio e arsênio, que são utilizadas na fabricação de produtos eletrônicos: TVs de plasma, smartphones e baterias, por exemplo, entre outros elementos que sem o devido tratamento, tornam-se substâncias tóxicas nocivas a existência. (CERRI, 2016, n.p.)

Tereza Cristina M. B. Carvalho, Coordenadora do CEDIR - Centro de Centro de Descarte e Reuso de Resíduos de Informática, apresentou no $V$ Fórum da Agenda Ambiental na Administração Pública, estudos sobre os efeitos dessas substâncias tóxicas no ser humano e onde são utilizadas:

[...] chumbo: Causa danos ao sistema nervoso e sanguíneo. Onde é usado: Computador, celular, televisão. Mercúrio: Causa danos cerebrais e ao fígado. Onde é usado: Computador, monitor e TV de tela plana. Cádmio: Causa envenenamento, danos aos ossos, rins e pulmões. Onde é usado: Computador, monitores de tubo antigos, baterias de laptops. Arsênico: Causa doenças de pele, prejudica o sistema nervoso e pode causar câncer no pulmão. Onde é usado: Celular. PVC: Se queimado e inalado, pode causar problemas respiratórios. Onde é usado: Em fios, para isolar corrente. Belírio: Causa câncer no pulmão. Onde é usado: Computador, celular. Retardantes de chamas (BRT): Causam desordens hormonais, nervosas e reprodutivas. Onde é usado: Diversos componentes eletrônicos, para prevenir incêndios [...]. (CARVALHO, 2010, n.p.)

Muitas vezes os efeitos nocivos das toxinas encontradas no e-lixo ou e-waste, termo utilizado nos Estados Unidos para identificar o lixo eletrônico, ainda são desconhecidos, pois a grande maioria ainda passa por fase de testes. Igualmente, não é possível prever a longo prazo os danos que podem ser causados ao ser humano tampouco ao meio ambiente e, neste propósito, o mais adequado para evitar maiores prejuízos ou amortizar os riscos, é implementar o ora estabelecido pela Lei de Política Nacional de Resíduos Sólidos - PNRS, especificamente o instituto da logística reversa - declarada como um dos instrumentos da PNRS pela lei supra e regulamentada pelo Decreto n. 07.404 de 23 de dezembro de 2010, tendo em conta o teor do artigo 15 (BRASIL, 2010, n.p.) -, apresenta-se como a solução mais plausível e atual - debatida em setembro de 2017 pela Deliberação n.o 11 do Comitê Orientador para Implementação de Sistemas de Logística Reversa - CORI, com diretrizes para a atuação dos agentes públicos, iniciativa privada e sociedade civil nas atividades ligadas à área (DIÁRIO OFICIAL DA UNIÃO, 2017, p. 49), ou seja, no que tange os resíduos oriundos do avanço tecnológico, tema que será oportunamente discutido adiante. 
Nota-se que em decorrência do vigor das novas tecnologias, o setor produtivo detém cada vez mais condições técnicas para alimentar a cadeia de produção, mas que, contudo, para manter a margem crescente de lucros a partir do consumo, viu a necessidade de reduzir a vida útil dos bens, dando formato ao fenômeno da obsolescência programada, para que mais bens fossem produzidos e assim consumidos. A consequência disso tudo foi o aumento o número do descarte dos produtos e o acúmulo de lixo eletrônico, que na maioria das vezes não tem a destinação adequada para sua decomposição ou reutilização de resíduos.

O aumento no volume do lixo eletrônico que é descartado inadequadamente em lixões ou aterros sanitários causa diversos efeitos danosos ao meio ambiente, podendo ocorrer vazamento de produtos químicos e metais pesados, o denominado chorume, que poderá infiltrar no solo e acabar contaminando o lençol freático. Outros problemas também poderão ocorrer nesses aterros, tais como, a queima e a destruição de equipamentos eletrônicos que acabam por promover a vaporização de mercúrio. Além disso, incêndios não controlados podem ocorrer nos aterros sanitários e quando expostos ao fogo, metais e outras substâncias químicas e tóxicas podem ser liberados, causando danos graves ao meio ambiente e a população.

A solução para uma fatia considerável desta gama de problemas é implementar efetivamente o que dispõe a Lei de Política Nacional de Resíduos Sólidos, com atenção especial para o instrumento da logística reversa que se manifesta como a solução viável para o alcance do desenvolvimento econômico e social, pois tem no seu núcleo a preocupação em implementar um conjunto de ações dedicadas a todo o ciclo de vida produtivo, cuja destinação final deve ser a mais ambientalmente adequada.

Em um estudo apresentando no XXVIII Encontro Nacional de Engenharia de Produção ocorrido no Rio de Janeiro/RJ em 2008, Karen Maria da Costa Mattos, Katty Maria Da Costa Mattos e Wattson José Saenz Perales, avaliaram que:

A logística reversa começa quando o produto é consumido e, neste momento, a empresa deve estar preparada para o que Staff (2005) chama de 4'Rs da logística reversa: Recuperação, Reconciliação, Reparo e Reciclagem. Recuperação: permite à empresa manter e controlar a saída e a confiabilidade do produto de forma a estar sempre melhorando seu produto no mercado. Reconciliação: é a análise dos produtos defeituosos que retornam para empresa; eles são avaliados e, caso não haja problema, os mesmos são re-estocados para serem enviados ao mercado. Reparo: é o tempo de espera do cliente para que o produto seja reparado ou trocado. Reciclagem: é o retorno ao ciclo dos produtos que seriam descartados pelo consumidor e pela indústria de forma que 
reduzam os custos do processo e abram novas possibilidades. (MATTOS, Karen; MATTOS, Katty; PERACLES, 2008, n.p.)

Parece mesmo que a logística reversa apresenta-se como fundamento para garantir a existência humana pautada no consumo, motivando os agentes econômicos e sociais a atuarem em prol da qualidade e da perpetuação da vida humana, o que vem sendo ignorado pela sociedade contemporânea, consistindo numa rede de cooperação que deve imperar entre consumidores (devolução dos produtos em locais específicos), empresas (retirada e definição entre reciclagem ou reutilização), administração pública (atos de fiscalização, além de diversas atividades educativas, informativas e, fundamentalmente, de conscientização da sociedade).

$\mathrm{Na}$ primeira seção deste artigo ressaltou-se que o consumo tem se tornado uma obrigação cívica e moral, o indivíduo é reduzido à qualidade de consumidor e a sua dignidade humana encontra-se inserida no processo de coisificação. Eduardo Galeano faz uma análise sobre esta afirmativa: "[...] as coisas importam cada vez mais e as pessoas cada vez menos, os fins foram sequestrados pelos meios: as coisas te compram, o automóvel te governa, o computador te programa a TV te vê." (GALEANO, 2001, p. 255)

Portanto, no momento que a qualidade de vida confunde-se com a quantidade e modernidade dos bens de consumo lançados no mercado e colocados a disposição do consumidor, fundamentando o fenômeno da obsolescência, verifica-se também a confusão do valor do uso com o do possuir. Pensar então no consumo como algo intrínseco a existência humana é arrazoar que se trata de um direito de todos, portanto, a sociedade contemporânea não pode usurpar da condição consumerista em prol da satisfação dos seus desejos insaciáveis, sob pena de colocar as futuras gerações em um estado de incerteza e risco.

Nestes termos, na sociedade contemporânea, o instrumento da lógica reversa apresenta-se como base para o vigor do princípio da sustentabilidade, funcionando a produção e o consumo em um formato mais adequado à preservação dos pilares ambiental e social, sem anular ou demonizar o econômico.

Destarte, a produção e o uso de bens e serviços, estarão mais bem condicionados para proporcionar qualidade de vida as gerações presentes, amortecendo o uso dos recursos naturais e redirecionando os materiais tóxicos para finalidade apropriada, sem arriscar as expectativas das futuras. (BRASIL, 2015, n.p.)

A Lei Federal n. 12.305, de 2 de agosto de 2010, que instituiu a Política Nacional de Resíduos Sólidos, depois de mais de duas décadas de tramitação no Congresso Nacional, passando o texto original por várias modificações, veio compor o rol legislativo brasileiro, 
trazendo em seu texto, objetivos, princípios, instrumentos e diretrizes para a gestão agregada e ao gerenciamento dos resíduos sólidos, determinando responsabilidades para os integrantes da sociedade de consumo e ainda, ditando os instrumentos econômicos sobre a temática.

O inciso XV do artigo 7ำ da lei, aponta para a diminuição da produção de resíduos sólidos e a repreensão do consumismo: "XV - estímulo à rotulagem ambiental e ao consumo sustentável."

Já o inciso IV do artigo 60, aponta expressamente como um dos seus princípios, o desenvolvimento sustentável, que, entretanto, para a sua concretização, carece de alguns objetivos, contidos em incisos do artigo 70: A) "III - estímulo à adoção de padrões sustentáveis de produção e consumo de bens e serviços;"; B) "XI - prioridade, nas aquisições e contratações governamentais, para: [...] b) bens, serviços e obras que considerem critérios compatíveis com padrões de consumo social e ambientalmente sustentáveis;"; C) "XIV - incentivo ao desenvolvimento de sistemas de gestão ambiental e empresarial voltados para a melhoria dos processos produtivos e ao reaproveitamento dos resíduos sólidos, incluídos a recuperação e o aproveitamento energético;"; e D) "XV - estímulo à rotulagem ambiental e ao consumo sustentável".

A Lei de Política Nacional de Resíduos Sólidos assinala dois aspectos: a) o estímulo à rotulagem ambiental e ao consumo sustentável (art. 70, XV); e b) a ecoeficiência, cingida pela definição de produção sustentável (art. 6ำ, V).

Contudo, é o instrumento da logística reversa, previsto no inciso XII do artigo 3 o da lei em comento ${ }^{3}$, declarada como um dos instrumentos da PNRS pela lei supra e regulamentada pelo Decreto $\mathrm{n} . \mathbf{0} 7.404$ de 23 de dezembro de 2010, tendo em conta o teor do artigo 15 (BRASIL, 2010, n.p.) -, revela maior esperança de efetividade para a pretensão destacada neste trabalho, por manifestar atenção com todo o ciclo de vida dos produtos da produção ao pósconsumo, agregando a sociedade pós-moderna valores sustentáveis. mais plausível, além de tratar de um tema atual, então debatida em setembro de 2017 pela Deliberação n.o 11 do Comitê Orientador para Implementação de Sistemas de Logística Reversa - CORI, com diretrizes para a atuação dos agentes públicos, iniciativa privada e sociedade civil nas atividades ligadas à área (DIÁRIO OFICIAL DA UNIÃO, 2017, p. 49).

\footnotetext{
${ }^{3}$ XII - logística reversa: instrumento de desenvolvimento econômico e social caracterizado por um conjunto de ações, procedimentos e meios destinados a viabilizar a coleta e a restituição dos resíduos sólidos ao setor empresarial, para reaproveitamento, em seu ciclo ou em outros ciclos produtivos, ou outra destinação final ambientalmente adequada;
} 
A logística reversa é assim o elemento, disposto no ordenamento jurídico brasileiro, mais propenso a colaborar para o equilíbrio do desenvolvimento socioeconômico, com vias a enfrentar o fenômeno da obsolescência programada, induzindo a sociedade de consumo para uma compreensão de produtos cujo ciclo de vida seja mais longo e mais útil do que o sugerido pela patologia do consumismo pós-moderno, a fim de se adotar modelos verdadeiramente sustentáveis de produção e consumo.

\section{CONSIDERAÇÕES FINAIS}

Com base na discussão levantada no trabalho, ressaltou-se que o ato de consumir é inerente à existência humana e se faz presente desde os primórdios na humanidade. Todavia, com as mudanças ocorridas ao longo da história, o consumo tornou-se base absoluta de sustentação do desenvolvimento econômico - situação que juntamente com a inserção das novas tecnologias - colaborou significativamente para ampliar sua prática reiterada elevando-o a um nível desordenado, o consumismo.

$\mathrm{O}$ ato de consumir deixou de ser realizado apenas para suprir as necessidades básicas de subsistência da humanidade e vem sendo utilizado como critério imprescindível à inclusão e autoafirmação social do indivíduo/consumidor inserido no contexto da sociedade pós-moderna.

Dentre as várias causas de aumento do consumo, cuidou a pesquisa de destacar os riscos oriundos da prática empresarial em fomentar o fenômeno da obsolescência programada que sob o argumento voraz da obtenção de lucros - dedica-se a alimentar uma cadeia de produção de bens com uma vida útil cada vez menor, promovendo um retrocesso da própria condição humana.

A prática da obsolescência coloca em riscos as gerações presentes e futuras, devido a extração desmedida de recursos naturais e o descarte de produtos e resíduos - visando incutir precipuamente no consumidor e no mercado de consumo - a necessidade da aquisição de cada vez mais bens - tornando assim, o consumo uma prática reiterada e naturalizada.

O consumo desmedido atrelado às práticas antiéticas e os resultados da obsolescência programada, vem estimulando a economia sem preocupar-se com os pilares social e ambiental - isso considerando a redução proposital da vida útil dos bens, o aumento do consumo e a despreocupação com a extração e os resíduos descartados - tem provocado consequências gravosas à sociedade e irreversíveis ao meio ambiente, colocando-o em iminente risco de degradação e por consequência da própria existência humana digna. 
A proposta apresentada no presente artigo foi chamar a atenção para o que já se encontra positivado no rol legislativo brasileiro, o instrumento da logística reversa previsto na Lei de Política Nacional de Resíduos Sólidos, com vias a garantir a eficácia do desenvolvimento econômico e social, partindo de ações conjuntas preocupadas com todo ciclo de vida dos bens produzidos e inclusive, para que a destinação final destes, seja ambientalmente adequada.

Desta feita, a logística reversa é apresentada como a esperança plausível para a proteção ambiental, atentando-se as necessidades desta e das futuras gerações, dedicando justiça e equidade aos aspectos econômico, social e ambiental, promovendo assim, um modelo efetivo de desenvolvimento sustentável.

Conclui-se, por fim, que é por meio da Lei de Política Nacional de Resíduos Sólidos e, especialmente da positivação da logística reversa, que a problemática suscitada encontra subsídios para alcançar o grau de necessidades da sociedade de consumo. Incumbindo aos agentes econômicos e sociais, o dever de empenho em suas ações e em todo o ciclo de vida do produto - alvitrando a produção de bens com maior durabilidade e com materiais menos nocivos - garantindo assim, à posteridade o direito fundamental, imprescritível e irrenunciável a um meio ambiente equilibrado.

\section{REFERÊNCIAS}

BAUMAN, Zygmunt. O mal-estar da pós-modernidade. Tradução de Mauro Gama e Claudia Martinelli Gama. Rio de Janeiro: Zahar, 1998.

Vida líquida. Tradução de Carlos Alberto Medeiros. Rio de Janeiro: Jorge Zahar, 2007.

BELLANDI, Daniel; AUGUSTIN, Sérgio. Obsolescência programada, consumismo e sociedade de consumo: uma crítica ao pensamento econômico. XXIV Encontro Nacional do Conpedi - UFS: Direito, Globalização e Responsabilidade nas Relações de Consumo. (Coord.) Viviane Coêlho de Séllos Knoerr; Joana Stelzer, Keila Pacheco Ferreira. Florianópolis: CONPEDI, 2015. Disponível em: <http://www.conpedi.org.br/publicacoes/c178h0tg/i9jl1a02/WQM34KU694IWz9h9.pdf>. Acesso em 16 jan. 2018.

BOTSMAN, Rachel; ROGERS, Roo. O que é meu é seu: como o consumo colaborativo vai mudar o nosso mundo. Tradução de Rodrigo Sardenberg. Porto Alegre: Bookman, 2011.

BRASIL. Decreto no 7.404, de 23 de dezembro de 2010: Regulamenta a Lei no 12.305, de 2 de agosto de 2010, que institui a Política Nacional de Resíduos Sólidos, cria o Comitê Interministerial da Política Nacional de Resíduos Sólidos e o Comitê Orientador para a Implantação dos Sistemas de Logística Reversa, e dá outras providências. Disponível em: < http://www.planalto.gov.br/ccivil_03/_ato2007-2010/2010/decreto/d7404.htm>. Acesso em 16 jan. 2018. 
Lei n.o 12.305, de 2 de agosto de 2010: institui a Política Nacional de Resíduos Sólidos; altera a Lei no 9.605, de 12 de fevereiro de 1998; e dá outras providências. Disponível em: <http://www.planalto.gov.br/ccivil_03/_ato2007-2010/2010/lei//12305.htm>. Acesso em 16 jan. 2018.

Responsabilidade socioambiental. Disponível em: <http://www.mma.gov.br/responsabilidade-socioambiental>. Acesso em 16 jan. 2018.

BRESSER-PEREIRA, Luiz Carlos. Modernidade neoliberal. Revista Brasileira de Ciências Sociais. v. 29, n. 84, São Paulo Feb. 2014. Disponível em: $<$ http://www.scielo.br/scielo.php?script=sci_arttext\&pid=S0102-69092014000100006>. Acesso em 16 jan. 2018.

CARVALHO, Eduardo. Lista global põe Petrobras entre as 20 empresas que mais poluíram em 2013. Disponível em <http://g1.globo.com/natureza/noticia/2014/12/lista-global-poepetrobras-entre-20-empresas-que-mais-poluiram-em-2013.html>. Acesso em 16 jan. 2018.

CARVALHO, Tereza Cristina M. B. CEDIR Centro de Descarte e Reuso de Resíduos de Informática. São Paulo: V Fórum da Agenda Ambiental na Administração Pública (A3P), 2010. 52 slides: da cor branca. Acompanha texto. Disponível em: <http://www.mma.gov.br/estruturas/a3p/_arquivos/6_cedir_tereza_carvalho_36.pdf > Acesso em 16 jan. 2018.

CERRI, Alberto. Mercúrio, cádmio e chumbo: os inimigos íntimos presentes nos eletrônicos. Ecycle: sua pegada mais leve. Disponível em: $<$ http://www.ecycle.com.br/component/content/article/35/428-mercurio-cadmio-e-chumboos-inimigos-intimos-presentes-nos-eletronicos.htm>. Acesso em 16 jan. 2018.

COMPRAR, tirar comprar: La história secreta de la obsolescência planejada. Produção de Cosima Dannoritzer, $2011 . \quad$ (52m18s). Disponível em: <http://www.youtube.com/watch?v=XW5pOx2ZI9c>. Acesso em 16 jan. 2018.

COSTA, Daniela Viegas da; TEODÓsıO, Armindo dos Santos de Sousa. Desenvolvimento sustentável, consumo e cidadania: um estudo sobre a (des)articulação da comunicação de organizações da sociedade civil, do estado e das empresas. RAM - Revista de Administração Mackenzie, v. 12, n. 3, São Paulo, June 2011. Disponível em: <http://www.scielo.br/scielo.php?script=sci_arttext\&pid=S1678-69712011000300006>. Acesso em 16 jan. 2018.

Diário Oficial da União, Brasília, DF, № 185, terça-feira, 26 de setembro de 2017, p. 49, Seção I, ISSN 1677-7042. Disponível em: <http://pesquisa.in.gov.br/imprensa/jsp/visualiza/index.jsp?jornal=1\&pagina=49\&data=26/09/2 017>. Acesso em 16 jan. 2018.

ELKINGTON, John. Sustentabilidade: canibais com garfo e faca. Tradução de Laura Prades Veiga. São Paulo: M.Books do Brasil Editora Ltda., 2012.

FORENSE, Direito Legal - Diário. Mais da metade dos eletrônicos é substituída: obsolescência. Disponível em: <http://www.direitolegal.org/direito-do-consumidor/mais-da-metade-dos- 
equipamentos-eletronicos-e-substituida-devido-a-obsolescenciaprogramada/\#sthash.fhZv4ZDf.dpuf>. Acesso em 16 jan. 2018.

GALEANO, Eduardo. De pernas pro ar: a escola do mundo ao avesso. Tradução de Sérgio Faraco. 9. ed. Porto Alegre: L\&PM, 2001.

GARCIA, Diego. O que é obsolescência programada? Mundo Estranho. 2014. Disponível em: $<$ http://planetasustentavel.abril.com.br/noticia/desenvolvimento/obsolescencia-programadaos-produtos-sao-feitos-para-durar-pouco-778525.shtml>. Acesso em 16 jan. 2018.

IDEC; MARKET ANALYSIS. Ciclo de vida de eletroeletrônicos. Disponível em: <http://www.idec.org.br/uploads/testes_pesquisas/pdfs/market_analysis.pdf>. Acesso em 16 jan. 2018.

JACOBI, Pedro. Resenha Book Reviews: Sustentabilidade Ambiental, Consumo e Cidadania. Ambiente \& Sociedade. v. 9, n. 1, Campinas, Jan./June 2006. Disponível em: $<$ http://www.scielo.br/scielo.php?script=sci_arttext\&pid=S1414-753X2006000100010 $>$. Acesso em 16 jan. 2018.

LIMA, Gabriela Eulalio de; ANDRADE, Sinara Lacerda. A sociedade de consumo pós-moderna e a influência das novas tecnologias: obsolescência programada e obsolescência psicológica. XXIV Congresso Nacional do CONPEDI - UFMG/FUMEC/Dom Helder Câmara: Direito e Sustentabilidade II. (Coord.) José Claudio Junqueira Ribeiro, Mônica Bonetti Couto, Ingo Wolfgang Sarlet. Florianópolis: CONPEDI, 2015.2 Disponível em: <http://www.conpedi.org.br/publicacoes/66fsl345/t9513697/N35xifFbA81zPLJ6.pdf>. Acesso em 16 jan. 2018.

MATTOS, Karen Maria da Costa; MATTOS, Katty Maria Da Costa; PERACLES, Wattson José Saenz. Os impactos ambientais causados pelo lixo eletrônico e o uso da logística reversa para minimizar os efeitos causados ao meio ambiente. Disponível em: <http://www.abepro.org.br/biblioteca/enegep2008_TN_STP_077_543_11709.pdf >. Acesso em 16 jan. 2018.

MIGALHAS. Apple é processada por evoluir o iPad rápido demais. Disponível em: $<$ http://www.migalhas.com.br/Quentes/17,Ml172979,11049-

Apple+e+processada+por+evoluir+o+iPad+rapido+demais>. Acesso em 16 jan. 2018.

PACKARD, Vance. Estratégia do desperdício. São Paulo: Ibrasa, 1965.

REIS, Margarida Maria de Oliveira; CASTRO, Gardenia de. As rupturas tecnológicas na sociedade da informação. Revista ABC. Disponível em: <https://revista.acbsc.org.br/racb/article/view/408/515>. Acesso em 16 jan. 2018.

RUSCHEINSKY, Aloísio. Distinção e desigualdades na cultura de consumo. Caderno CRH. v. 23, n. 59, Salvador May/Aug. 2010.2 Disponível em: <http://www.scielo.br/scielo.php?script=sci_arttext\&pid=S0103-49792010000200014>. Acesso em 16 jan. 2018. 
SIMS, Cynthia. Ética, consumo e interdependência planetária. Sociedade e Estado. v. 28, n. 1, Brasília, Jan./Apr. $2013 . \quad$ Disponível em: $<$ http://www.scielo.br/scielo.php?script=sci_arttext\&pid=S0102-69922013000100010>. Acesso em 16 jan. 2018.

SLADE, Giles. Made to break: technology and obsolescence in America. Cambridge: Harvard University Press, 2006.

ZAMBON, Antonio Carlos; et. al. Obsolescência acelerada de produtos tecnológicos e os impactos na sustentabilidade da produção. RAM - Revista de Administração Mackenzie, v. 16, n. 4, São Paulo, July/Aug. 2015.2 Disponível em: <http://www.scielo.br/scielo.php?script=sci_arttext\&pid=S1678-69712015000400231>. Acesso em 16 jan. 2018.

Trabalho enviado em 29 de setembro de 2017. Aceito em 13 de fevereiro de 2018. 